\title{
A SOCIEDADE CAPITALISTA PÓS-MODERNA E SUAS REPERCUSSÕES NAS RELAÇÕES DE TRABALHO SUBORDINADAS: A questão da propriedade dos inventos criados pelo empregado
}

\section{THE POSTMODERN CAPITALIST SOCIETY AND THE LABOUR RELATIONS REPERCUSSIONS: The issue of ownership of inventions created by the employee}

\author{
Nilton Cesar Flores ${ }^{2}$ \\ Doutor em Direito \\ Universidade Estácio de Sá - Rio de Janeiro (RJ) - Brasil \\ e \\ Juliana Monteiro 3 \\ Mestranda em Direito \\ Universidade Estácio de Sá - Rio de Janeiro (RJ) - Brasil
}

RESUMO: Este artigo colima abordagem relativa ao direito de propriedade dos inventos produzidos pelos empregados na constância de suas relações de emprego subordinadas. 0 desenvolvimento do capitalismo e da modernidade, e das inegáveis transformações vivenciadas no contexto social em plena era de transição paradigmática, de globalização, sociedade de consumo, interligada por uma rede mundial de computadores, da comunicação, da informação e todos os seus reflexos, são desenvolvidos e utilizados como pano de fundo para uma abordagem profunda do tema. 0 objetivo geral deste trabalho é o de destacar, desde o início, reflexões que visem a minimizar ou até mesmo tentar solucionar o problema apontando. Neste contexto, a premente necessidade de maior conscientização

\footnotetext{
${ }^{2}$ Doutor pela UFSC; Coordenador-Adjunto do Programa de Mestrado e Doutorado da UNESA; professor adjunto de Direito Empresarial da UFF, professor convidado da FGV; professor da Escola de Magistratura do Rio de Janeiro EMERJ; Coordenador do Grupo de Pesquisa de Direito Ambiental e Propriedade Intelectual - GEDAPI certificado pelo CNPq e reconhecido pela UFF. E-mail: cesarflores2004@hotmail.

${ }^{3}$ Advogada, Graduada pela Universidade Federal do Rio de Janeiro, Pós-Graduada pela Universidade Estadual do Rio de Janeiro e mestranda em Direito Público e Evolução Social, na linha de pesquisa Direitos Fundamentais e Novos Direitos da Universidade Estácio de Sá - UNESA. E-mail: prof.julianamonteiro@gmail.com.
} 
social, de um maior diálogo entre as áreas do saber, como: a Sociologia, a Filosofia e o Direito e, em especial, a importância do papel do Legislativo mas, sobremaneira, do Judiciário, a fim de coadunar o Direito e a técnica e, assim, conseguir atingir o tão almejado equilíbrio das relações sociais. Metodologicamente se pretende analisar o tema sociológico-reflexivamente para obter o enfoque crítico necessário acerca da questão da propriedade dos inventos.

Palavras-chaves: Globalização. Propriedade Industrial. Relação de Emprego.

Abstract: This article approach relative to the ownership of the inventions produced by employees in the constancy of their employment relations subordinate. The development of capitalism and modernity, and the undeniable changes experienced in the social context in the era of paradigm shift, globalization, consumer society, interconnected by a global network of computers, communication, information and all your reflexes are developed and used as a backdrop for a deep approach theme. The aim of this study is to highlight, from the beginning, reflections that aim to minimize or even try to solve the problem pointing. In this context, the urgent need for greater social awareness, a greater dialogue between disciplines, such as sociology, philosophy and law, and in particular the importance of the role of the Legislature but greatly in the judiciary, in order consistent with the law and technology, and thus able to achieve the much desired balance of social relations. Methodologically, we intend to analyze the topic through a sociological analysis - reflective, get critical focus on the issue of ownership of inventions.

Keywords: Employment Relationship. Globalization. Industrial Property.

\section{INTRODUÇÃO}

O presente artigo visa uma análise da evolução histórica do capitalismo ao longo dos séculos e a demonstração de sua direta e inegável influência nas relações sociais, sobremaneira, nas relações de trabalho subordinadas, perpassando por todas as mudanças e transformações sociais, até adentrar na questão do direito de propriedade dos inventos criados pelos empregados. 
A transição da modernidade para uma nova realidade, para a qual não há um consenso terminológico, mas há grande preocupação com os efeitos nefastos que vem causando, é cenário para o desenvolvimento do raciocínio e de uma abordagem crítico-construtiva.

De fato, a expansão desenfreada do capitalismo, aliada ao um novo modelo de exploração da mão de obra, pautado na intensificação do trabalho de produtividade, vem revelando uma profunda mudança de paradigma e ensejando uma preocupação com o futuro.

A proteção existente, em muitos momentos, se revela insuficiente e defasada, não atende mais às demandas que surgem como fruto de uma sociedade capitalista pós-moderna, globalizada e em constante transformação.

A dinâmica capitalista se confirma ao longo dos tempos, apesar dos momentos de crise, o capitalismo vem se reinventando e, hoje, amparado por um aparato tecnológico, dinâmico e eficiente ganha proporções dantescas e alarmantes de exploração humana e desgaste ambiental.

A produtividade passa a ser o objetivo central, em detrimento das preocupações com o ser humano e com a natureza, gerando notório desgaste, aonde só sobrevive aquele que for veloz, versátil, eficiente, e der conta das metas, quase inatingíveis, em tempo recorde.

Desta feita, a análise perpassa, inicialmente, por todas as fases do capitalismo, do liberal ao desorganizado. Em um segundo momento, constatamos como o capitalismo e a modernidade, passam a não mais se dissociar, apesar das mudanças paradigmáticas sofridas ao longo dos séculos e, consequentemente, quais os reflexos dessas transformações. As consequências dessa mudança paradigmática nas relações de trabalho subordinado são objeto de análise, revelando o fenômeno da intensificação do trabalho, baseado na produtividade. Um capitalismo contemporâneo globalizado voltado para os resultados. Por fim, a análise cinge-se a um ponto específico dentro deste atemorizante contexto: a questão do direito de propriedade quanto aos inventos criados pelo empregado.

A questão pende de uma regulação precisa, o direito não acompanha a velocidade com que as relações se transmudam em plena sociedade da informação, não possuindo respostas às demandas, instaurando um momento de insegurança social e jurídica.

Deste modo, uma análise histórico-filosófico-social se fará presente ao longo da explanação, a fim de que possamos nos conscientizar e revelar esforços, tanto 
preventivos quanto aptos a encontrar soluções para as questões já existentes. 0 tempo urge.

A pós-modernidade e a mudança de paradigma da exploração nas relações de trabalho subordinadas reflete uma realidade e tem como grande marco filosófico, justamente, o aumento gradativo de uma desvalorização do judiciário por conta da injustiça e insegurança. Os juízes precisam se conscientizar e lançar esforços dada a importância de seu papel inserido na sociedade da informação, que traz demandas que ele tem que decidir, pois a lei não traz regulação nem sequer solução.

A proposta consiste em alertar para essa situação de insegurança e, trazer parâmetros para uma atuação preventiva, através da criação de regras gerais aptas a balisar as decisões e, mais ainda, a atuação consciente do judiciário neste sentido.

A grande preocupação, contudo, é evitar mera falácia, mas sim, ir em busca de ações concretas. Como assevera René Descartes em seu “Discurso do Método", o grande problema do Direito reside em deixar a questão no plano filosófico e não conseguir resolver no campo prático.

\section{O Capitalismo e a Pós-modernidade}

\subsection{Do capitalismo liberal ao capitalismo “desorganizado"}

O capitalismo teve seu berço na Europa, mais precisamente na Inglaterra, e foi a partir das revoluções liberais da Idade Moderna, como a Revolução Inglesa (1640-60), a Revolução Francesa (1789-99), dentre outras, que fizeram com que o capitalismo se estabelecesse e se desenvolvesse como sistema econômico predominante nos países da Europa Ocidental. E assim, teve início a era do capitalismo moderno.

O capitalismo e a modernidade ocidental, a partir de então, apesar de todas as transformações que se seguiram e de corresponderem a processos históricos autônomos e distintos, passaram a estar ligados entre si em todas as fases do capitalismo: o liberal, o organizado e o desorganizado 4.

\footnotetext{
${ }^{4}$ Boaventura Santos defende que podemos dividir esse desenvolvimento em três períodos: o primeiro, do capitalismo liberal, cobre todo o século XIX, embora as três últimas décadas tenham um caráter de transição; o segundo, o período do capitalismo organizado, começa nos finais do século XIX e atinge o seu desenvolvimento máximo no período entre as duas guerras e nas duas primeiras décadas do após-guerra; finalmente, o terceiro período, o capitalismo desorganizado, começa nos finais dos anos 60 e ainda continua. (SANTOS, 2000, p.139).
} 


\section{NILTON CESAR FLORES E JULIANA MONTEIRO}

Juntamente com o capitalismo, surge o embate capital versus trabalho e, duas classes antagônicas e em constante conflito, a burguesia e o proletariado, estando, nas mãos da classe burguesa, o poderio econômico e político, se sobrepondo à massa proletariada.

Desta feita, o século XIX consolidou a burguesia como classe dominante nos países capitalistas, inseriu o modelo capitalista liberal (SANTOS, 2000, p.139 e 146), um período de autorregulação das relações sociais e de mercado, garantido pelo Estado, pautado no direito privado e que vinculou, a partir daí, a própria trajetória do paradigma da modernidade ao capitalismo. Tratou-se de um período de grandes promessas e muita credibilidade no Estado, um projeto “demasiado ambicioso e internamente contraditório" (SANTOS, 2000, p.140), tanto assim que, no final do próprio século XIX, com a industrialização e a expansão do princípio do mercado, foi substituído pelo capitalismo organizado, que surgiu em meio a algumas promessas não cumpridas, porém mascaradas sob uma hegemonia estatal e sob uma atuação mais interventiva do Estado.

O desenvolvimento tecnológico, sem sombras de dúvida, contribuiu e foi decisivo para a evolução do capitalismo industrial organizado. A indústria manufatureira evoluiu para a produção mecanizada, possibilitando a constituição de grandes empresas, nas quais se implantou o processo de especialização da mão de obra e de divisão técnica do trabalho ${ }^{5}$. Porém, por detrás deste cenário de desenvolvimento, a exploração dos trabalhadores alcançou proporções tais que, a fim de garantir o equilíbrio das relações sociais, o Estado se viu obrigado a intervir nas relações salarias e consumeristas, na proteção dos empregos, nas indenizações, medidas estas, que resultaram "em um pacto social (entre o capital e o trabalho, sob a égide do Estado) tão inédito que conduziram a uma forma política nova: o Estado-Providência. ${ }^{\prime \prime}$

Todavia, apesar de todo o empenho estatal para tentar conter a crise, a situação caótica fruto da exploração e geradora de profundas desigualdades e

\footnotetext{
${ }^{5}$ Por várias décadas depois da segunda Guerra Mundial, o modelo Keynesiano da economia capitalista, baseado num contrato social entre o capital e o trabalho e num controle sutil dos ciclos econômicos nacionais por meio de medidas tomadas pelo poder estatal - elevação ou redução das taxas de juros, aumento ou diminuição de impostos, etc, --, teve um grande êxito e levou prosperidade econômica e a estabilidade social à maioria dos países que seguiam economias de mercado de caráter misto. Na década de 1970, porém, esse modelo atingiu os seus limites conceituais. (CAPRA, 2005, p. 174).

6A gestão econômica (o Keynesianismo) e a gestão política (o Estado-Providência) do capitalismo nos países centrais conduziram a um novo modo de regulação social que se designou por fordismo. Este modo de regulação baseia-se na convergência do desenvolvimento do princípio do Estado e do princípio do mercado, de forma a que os conflitos entre ambos sejam considerados provisórios, seletivos e até institucionalizados. (SANTOS, 2000, p. 148).
} 
insatisfações sociais, acabou por revelar o fracasso de todas as tentativas supra referidas e por culminar em guerras e grandes crises.

A primeira Guerra Mundial e as Grandes Crises de 1929 e 1933 transformaram significativamente o cenário mundial e o capitalismo também passou por profundas mudanças. 0 mercado capitalista passou a ser liderado pelos norte-americanos, sendo derrubada a hegemonia europeia e o capitalismo competitivo, para dar lugar a um capitalismo monopolista.

Não se pode olvidar, que concomitantemente a todos esses fatos, a partir de 1917, o sistema capitalista passou a ter que enfrentar um grande desafio, pois chegando a representar um terço da população, surgiu o socialismo.

As grandes nações capitalistas passaram a ver o bloco socialista como inimigo comum, ampliado a partir da segunda guerra mundial com a instauração de regimes comunistas nos países do leste europeu e com a revolução chinesa. Nesta época, grande parte dos recursos produtivos foi investida na indústria bélica e na exploração do espaço com fins militares.

Deste modo, na proporção que, o paradigma reformista do capitalismo organizado chegou ao colapso, entrou em cena a era do capitalismo desorganizado7. O Estado-Providência e seu modelo fordista entraram em crise a partir dos anos setenta e houve uma conscientização dos déficits até então causados à sociedade e que, muitas das promessas da modernidade, jamais seriam cumpridas.

$E$, essas transformações da infraestrutura social acarretaram, como consequência, a ruptura dos valores tradicionais dos diferentes grupos e classes, segundo Faria, “maior agressividade de comportamento, novos modos de reinserção sócio-política, a emergência de estruturas paralelas de representação ao lado dos mecanismos representativos tradicionais e, sobretudo, o aparecimento de novas demandas por segmentos sociais desfavorecidos e geradores de receita". (FARIA, 1991. p.24).

Com isso, o próprio capitalismo do século XX, que resistiu ao socialismo, vem passando por inúmeras crises. E o que assombra o intérprete é o lapso temporal que as separam. Parece progressivamente mais curto, com elevados índices de desemprego, inflação, instabilidade e o aumento da concorrência entre os grandes competidores.

\footnotetext{
${ }^{7}$ Esta designação, porém, é ambígua e traiçoeira, pois pode fazer crer que no período atual o capitalismo não é organizado, o que está longe de ser verdade. De fato, pode afirmar-se precisamente o contrário, que o capitalismo está hoje mais organizado do que nunca. A expressão capitalismo desorganizado significa, em primeiro lugar, que as formas de organização típicas do segundo período estão a ser gradualmente desmanteladas ou reconstruídas num nível de coerência muito mais baixo, e, em segundo lugar, que, precisamente, por esse processo estar a decorrer, é muito mais visível a demolição das antigas formas organizativas do que o perfil das novas formas que irão substituí-las. (SANTOS, 2000, p.153).
} 
Pode-se assim, apropriando-se das sábias palavras de Boaventura Santos, afirmar que:

desde a primeira vaga industrial - com a expansão das cidades comerciais e o aparecimento de novas cidades industriais no período do capitalismo liberal - até ao espetacular desenvolvimento dos mercados mundiais, com o aparecimento de sistemas de produção de dimensão mundial, a industrialização do Terceiro Mundo e a emergência de uma ideologia mundial de consumismo no atual período do "capitalismo desorganizado" - o pilar da regulação sofreu um desenvolvimento desequilibrado, orientado para o mercado. (SANTOS, 2000, p.57)

Deste modo, constata-se que a sociedade atual, em plena era da Revolução da Informática, fez o capitalismo, mais uma vez, se reinventar, mais flexível ${ }^{8}$ e consideravelmente ampliado?.

\section{2 - Modernidade, Pós-modernidade e Pós- Industrialidade}

Após constatar-se que a trajetória do paradigma da modernidade está ligada ao capitalismo e suas fases, o grande desafio consiste em definir, inicialmente, o que é modernidade.

Segundo Giddens, “a modernidade refere-se a um estilo, costume de vida ou organização social que emergiram na Europa a partir do século XVII e que ulteriormente se tornaram mais ou menos mundiais em sua influência" (GIDDENS, 1991, p. 11).

Hodiernamente, há um consenso de que a modernidade não se apresenta mais

\footnotetext{
${ }^{8} \mathrm{~A}$ tendência para uma relação salarial mais precária (alguns dirão mais flexível) tem sido simultaneamente, causa e efeito do declínio dos mecanismos corporativos (legislação social, justiça do trabalho, contratação coletiva, salários indiretos) e das organizações que os mobilizavam, principalmente dos sindicatos, que viram o número de filiados diminuir continuamente. (...) A segmentação nacional e transnacional dos mercados de trabalho, o aumento do desemprego e do subemprego, a difusão da ideologia cultural do consumismo, o conjunto de todos esses fatores contribuiu para descaracterizar as práticas de classe ou para impedir que se transformem eficazmente em política de classe. (SANTOS, 2000, p.156).

${ }^{9}$ Esse novo capitalismo é profundamente diferente do que se formou durante a Revolução Industrial e do que surgiu depois da Segunda Guerra Mundial. Caracteriza-se por três traços fundamentais: suas principais atividades econômicas são globais; suas principais fontes de produtividade e competitividade são a inovação, a geração de conhecimento e o processamento de informações; e ele se estrutura principalmente em torno de redes de fluxos financeiros. (CAPRA, 2005, p. 148).
} 
com a mesma roupagem após todas as transformações sofridas, contudo, não há consenso quanto a um aspecto terminológico e conceitual preciso para esse fenômeno.

Podemos dizer que estamos a atravessar um período de "transição paradigmática” (SANTOS, 2000, p.49); Giddens apresenta uma variedade de termos sugerida para essa transição: "sociedade da informação"; "sociedade de consumo"; “pós-modernidade”; “sociedade pós-industrial”. (GIDDENS, 1991. p. 11) Aos quais ainda podemos somar outros, como "sociedade da inteligência” ou "da comunicação” (ROSSO, 2008, p. 9). Ou, ainda, “sociedade de redes” (MANUEL CASTELLS apud CAPRA, 2005, p.143).

O fato é que houve, notoriamente, uma mudança estrutural do sistema: transformações institucionais nos deslocando de um sistema baseado na manufatura de bens materiais para outro relacionado mais centralmente com a informação. (GIDDENS, 1991, p.12)

Não obstante algumas críticas, podemos afirmar que o termo Pós-modernidade apresenta-se como o mais popular, e um dos grandes (GIDDENS, 1991, p.12 e; SANTOS, 2000, p. 49), senão o maior, responsável pela popularização da noção de pós-modernidade foi Jean-François Lyotard ${ }^{10}$.

Jean-François Lyotard representa o referencial teórico da pós-modernidade $^{11}$, baseado na linguagem e na comunicação como fontes de equilíbrio das relações sociais, a ponto de ousarmos a afirmar que influenciou o pensamento de grandes pensadores, como Michel Foucault, Jürgen Habermas, dentre outros.

De fato, as estruturas da modernidade foram abaladas e vivemos a insegurança e as incertezas desse período transicional ${ }^{12}$. Transformações de tal monta que, inseridas no contexto da sociedade capitalista globalizada,

\footnotetext{
10“A condição da pós-modernidade é caracterizada por uma evaporação da grand narrative - o "enredo" dominante por meio do qual somos inseridos na história como seres tendo um passado definitivo e um futuro predizível”. (GIDDENS, 1991, p. 12).

${ }^{11}$ BITTAR “estudar a pós-modernidade é, para Lyotard, fundamentalmente, desapegar-se das influências, e fontes de inspiração medievais ou modernas, dedicando-se à compreensão das práticas de linguagem, por meio das quais interagem atores linguísticos, uma vez que isto redunda em capacidade para produzir compreensão e entendimentos sociais". (LYOTARD apud BITTAR, 2005, p. 126 e 127).

12“'Assim, tornam-se assuntos démodé os grandes temas da modernidade: universalidade da lei; abstração das normas; consenso e vontade geral; universalidade dos direitos humanos; ordenamento jurídico como sistema fechado e completo; sociedade como organismo; essencialidade do caráter gregário do homem; soberania como um ponto inquestionável e incontrastável da constituição do Estado moderno; formas capitalistas de produção e competição fordista do espaço produtivo serial; entre outras questões. Em lugar do universalismo, o fragmentário; em lugar do centralismo, o periférico; em lugar do consenso omnium, os regionalismos; em lugar da igualdade, a identidade." (BITTAR, 2005, p. 131)
} 
perpassam pela economia, pela política, pelas relações sociais e, sobretudo, sobre as relações de trabalho ${ }^{13}$.

Apropriando-nos das palavras de Capra, ao citar Manuel Castells, podemos afirmar que, assim como a Revolução Industrial deu origem à "sociedade industrial” , assim também a nova Revolução da Informática está dando origem à "sociedade da informação" (CAPRA, 2005, p. 143).

$\mathrm{O}$ falido modelo industrialista de vida (fordismo-Keynesianismo) ${ }^{14}$ passou a ser engolido pelos anseios de uma sociedade capitalista globalizada, intensamente explorada e repleta de insatisfações, descrente diante das promessas frustradas e das questões não solucionadas ${ }^{15}$. As mudanças existem e são reconhecidas como tal, contudo, grande parte das questões que surgem perpetuam-se sem solução. Vivemos, hoje, em plena era da sociedade de consume (BAUMAN, 1999, p. 88), na qual, há a constante mobilização para incutir nos agentes sociais a adoção "espontânea" desse personagem altamente consumista. Ou seja, ao invés da buscar-se pela mão de obra, o que se busca são consumidores ávidos a desempenhar esse papel.

É assim que alguns autores entram em cena para chamar à atenção de que o referido período deveria ser reconhecido como um período de profunda instabilidade e, inseridos nesta empreitada, destacam uma Pós-Industrialidade ${ }^{16}$, distante, de igual sorte, de um consenso quanto às suas regras.

\footnotetext{
${ }^{13}$ Notórias transformações nas relações de emprego: Aposta no investimento de indústria (perfil de mão de obra, de baixa qualificação, mal remunerada, sem distinções muito grandes de hierarquia, baixo nível de interação e/ou participação nas políticas empresariais na relação empregador/empregado, excessivamente onerada em horas de trabalho, condições precárias de execução das atividades, prevalência de atividades físicas sobre as intelectuais) e sua substituição pelo investimento de serviços (perfil de mão de obra executiva, de alto custo empresarial, bem qualificada, com gradativas distinções de papel empresarial, maior nível de interação e/ou participação nas políticas empresariais na relação empregador/ empregado, com redução de horas de trabalho dedicadas ao local de trabalho, condições informatizadas e mecanizadas de execução das atividades, prevalência de atividades intelectuais sobre físicas), o que provoca a alteração das relações sociais, da fisiologia das relações de trabalho, bem como permite maior mobilidade na estruturação das culturas laborais (teletrabalho, trabalho à distância, horários de trabalho flexíveis, empresários internacionais etc). (BITTAR, 2005, p. 149) ${ }^{14} \mathrm{Os}$ economistas keynesianos concentraram-se na economia interna de cada país, desconsiderando os tratados econômicos internacionais e a rede comercial global que se tornava cada vez maior; esqueceram-se do imenso poder das empresas multinacionais, que se tornaram os elementos principais da cena econômica mundial; e por último, mas não menos importantes, ignoraram os custos sociais e ambientais das atividades econômicas, como ainda estão acostumados a fazer a maioria dos economistas. (CAPRA, 2005, p. 147).

${ }^{15}$ Assim é que a pós-modernidade nasce ambientada num contexto em que a sociedade se prepara para superar os arquétipos advindos do modelo industrialista de vida (fordismo-Keynesianismo). Concorrência, horas de trabalho, centros urbanos, massificação e consumismo, relações de exploração humana, problemas sociais, falta de orçamento público, crise de representatividade, falta de consciência política, flagelos sociais, militarização crescente dos polos de riqueza mundial, ineficácia da legislação, carência de fiscalização... são fatores talvez não previstos, ou não calculados, que começaram a assinalar a desordem e o caos no final do século. (BITTAR, 2005, p. 174).

${ }^{16} \mathrm{Assim}$, passa-se a identificar, ao lado da pós-modernidade, outro movimento, a que se tem chamado de pós-industrialidade, surgindo como forma de motivar/desmotivar e desafiar/aprovar as mentes quanto aos destinos possiveis da humanidade. (“...esta expressão empregada pelo sociólogo italiano Domenico Demais, como forma de carterizar uma sociedade marcada pelos seguintes fatores: sociedade da informação, do teletrabalho, da desindustrialização das formas de produção, da diversificação dos espaços de trabalho, da intelectualização progressiva das atividades profissionais. (BITTAR, 2005, p. 175).
} 
Pelo exposto, diante do contexto, só nos resta constatar que "só a partir da modernidade é possível transgredir a modernidade" e, que independentemente da nomenclatura atribuída ao fenômeno, vivemos uma mudança estrutural de paradigmas $^{17}$.

\section{A globalização e seus reflexos nas relações de trabalho subordinadas}

Todo esse cenário de mudanças paradigmáticas que passamos a vivenciar, sobretudo a partir do final do século XX, com reflexos econômicos, sociais, políticos, culturais, tecnológicos, que culminou com a criação da Organização Mundial do Comércio (OMC), foi batizado de globalização (CAPRA, 2005, p. 141).

De fato, não há consenso acerca de uma conceituação precisa do termo globalização, mas é certo que surgiu da expansão da ideologia econômica do liberalismo e da consequente necessidade de abertura de mercados entre os países.

A “globalização" está na ordem do dia; uma palavra da moda, um lema, uma encantação mágica, uma senha capaz de abrir portas de todos os mistérios presentes e futuros e que, boa ou nefasta, reflete um processo irreversível e que a todos afeta (BAUMAN, 1999, p.7).

Trata-se, sem dúvida, de um fenômeno tipicamente capitalista, fruto de uma série de fatores sociais como o período das grandes colonizações, a Revolução Industrial, as grandes Guerras Mundiais, o avanço do Liberalismo, os avanços tecnológicos, enfim, ligada intimamente aos momentos e fenômenos sociais que se sucedem no seio social.

A globalização pode ser definida, nas palavras de Anthony Giddens, como “a intensificação das relações sociais em escala mundial, que ligam localidades distantes de tal maneira que acontecimentos locais são modelados por eventos ocorridos a muitas milhas de distância e vice-versa. Este é um processo dialético”. (GIDDENS, 1991, p. 76).

Segundo Bauman ${ }^{18}$, compartilhando as idéias de Jowitt, a globalização é a "nova desordem mundial", com outro nome.

\footnotetext{
${ }^{17}$ Hoje a intervenção tecnológica pode prolongar as consequências, no tempo e no espaço, muito para além da dimensão do próprio ato através de nexos de causalidade cada vez mais complexos e opacos. (SANTOS, 2000, p.58).

18“Ao longo de toda a era moderna nos acostumamos com a idéia de que a ordem é equivalente a "estar no controle". É dessa suposição - quer bem fundada ou meramente ilusória - de "estar no controle" que mais sentimos falta." (GIDDENS, 1991, p. 65).
} 
O fato é que, a globalização, frise-se, não decorreu de mero acaso, tratando-se de um processo elaborado intencionalmente pelos grandes países capitalistas que compõem o "G7" (CAPRA, 2005, p. 150). "Em condições de modernidade e globalização, uma quantidade cada vez maior de pessoas vive em circunstâncias nas quais instituições desencaixadas, ligando práticas locais a relações sociais globalizadas, organizam os aspectos principais da vida cotidiana" (GIDDENS, 1991, p. 91).

Assim, podemos chegar a afirmar que a globalização vem gerando uma crise no próprio direito e, mais precisamente, no Direito do Trabalho, pois as relações de trabalho subordinadas sofrem diretamente com todas essas transformações.

Um mercado extremamente competitivo, no qual para sobreviver exige-se que seja o melhor e com menores preços, imbuído de um capitalismo selvagem, deixa à margem a observância de direitos sociais conquistados em detrimento da "sobrevivência".

O grande desafio e a grande preocupação, diante deste cruel panorama, encontra-se, justamente, em encontrar um equilíbrio, se é que ele existe e pode ser alcançado.

Portanto, necessária se faz, uma profunda reflexão sobre a possibilidade de realização da democracia e das garantias dos direitos fundamentais, diante desse processo de transformação nas relações de trabalho e na própria economia. 0 Estado do Bem-Estar Social, o Welfare State, entrou em crise e toda a sua filosofia introdutória, baseada na existência de um Estado protecionista e garantidor dos direitos do hipossuficiente passou a ser repensado.

De fato, essa situação desperta para uma análise crítica da sistemática e dos resultados da globalização, que começam a ser questionados.

Há quem defenda que - não obstante todas as mazelas decorrentes do sistema - seja a globalização um "mal necessário" e que, por estar incorporado à realidade mundial, refletiria um caminho sem volta.

Por outro lado, críticos ferrenhos do sistema lideram um movimento, denominado de antiglobalização, ou seja, são os anticapitalistas, se assim podemos dizer, são os que se opõem aos aspectos capitalistas-liberais da sociedade globalizada, e que apontam como alternativa a adoção do socialismo, do comunismo e até mesmo da anarquia.

A questão é complexa e, sem olvidar da preocupação com o meio ambiente e do próprio futuro da humanidade diante desta exploração desenfreada, o nosso 
foco se volta para a questão dos direitos sociais do trabalhador, como resguardá- los diante desta globalização capitalista.

$\mathrm{Na}$ "nova era", a modernidade, e para outros "a pós-modernidade", estamos vivendo uma evolução espantosa na eletrônica, na tecnologia, nas ciências, entre outros, e de forma paralela se construiu um conjunto extenso de discursos que conferem força e capacidade de se expandir a essas novas formas de poder, mas não há resposta para todos os anseios sociais e as celeumas que surgem no atuar desses agentes.

No campo das relações de trabalho, alternativas de sobrevivência despontam. No Brasil, muito embora os direitos trabalhistas sejam irrenunciáveis pelos próprios titulares do direito, que são os empregados, inseridos em uma estrutura protetiva e rígida, a própria ordem constitucional foi obrigada a adaptar-se às novas exigências sociais e prever hipóteses de flexibilização. Ou seja, através da pactuação de acordos e convenções coletivas de trabalho, na qual a participação dos sindicatos da categoria profissional é obrigatória, na forma do artigo $8^{\circ}$, IV e VI, da Carta Magna, direitos trabalhistas, respectivamente, como o salário e a jornada, podem ser, temporária e excepcionalmente, flexibilizados tendo como cerne a manutenção dos empregos em momentos de extrema crise no setor da economia e a própria saúde do mercado de trabalho.

Há quem defenda, porém que, a flexibilização não se demonstra suficiente e sustenta, no Brasil, a necessidade da adoção de uma desregulamentação, assim como adotada em outros países da América e Europa. Desregulamentar seria despir-se das legislações trabalhistas infraconstitucionais conquistadas até agora, mantendo apenas os direitos sociais assegurados na Constituição como espinha dorsal e, delegando para as partes, através da pactuação dos supracitados acordos coletivos e convenções coletivas de trabalho, a instrumentalização dos seus direitos sociais.

Difícil asseverar quem está com a razão, pois são meios diversos de tentar driblar a crise e assegurar os empregos e o tão sonhado equilíbrio das relações sociais de trabalho. Assim, o que não se pode olvidar, é de que se trata de relação extremamente desigual, na qual o empregado é o hipossuficiente. $\mathrm{E}$, diante disso, mister se faz alertar que corremos o risco de uma regressão, ao contrário do avanço e solução almejados. Há o grande risco de que a parte mais forte da relação empregatícia, espelhada na figura do patrão capitalista e inserido em um mercado altamente competitivo, faça valer, de vez, a sua força em detrimento 
à observância dos direitos sociais dos trabalhadores, já conquistados. 0 que, de fato, já vem acontecendo aos poucos pautado no discurso da sociedade capitalista de consumo.

\section{A sociedade de consumo: do trabalho material ao imaterial}

A sociedade de consumo (BAUMAN, 1999, p. 90), como toda a sociedade moderna, é estratificada e envolve, sobretudo, o esquecimento, não o aprendizado. A pressão, hoje, é para romper os hábitos do trabalho regular, permanente, cronometrado, fixo, em prol do "trabalho flexível"19. A estratégia é fazer com que os trabalhadores esqueçam, não aprendam, o que quer que lhes pretendia ensinar a ética do trabalho nos dias dourados da indústria moderna ${ }^{20}$.

Capra, segundo a doutrina da globalização econômica denominada "neoliberalismo", desenvolveu a ideia do impacto social da globalização, mediante a apresentação proposta por Manuel Castells, o qual concluiu que a "economia em rede" transformou profundamente as relações sociais entre o capital e o trabaIho. (CAPRA, 2005, p. 153).

Seguindo em sua concepção neoliberal, aduziu que o declínio da soberania, autoridade e legitimidade dos Estados nacionais foi decorrência direta da ascensão desta sociedade em rede, o que gerou uma profunda transformação das relações de poder, que deixa de ser, por exemplo, nas relações empresariais, um processo controlador e linear e passa, na sociedade em rede, a se portar de modo difuso, não linear, imprevisível. (CAPRA, 2005, p. 163).

Os tempos, de fato, mudaram e, a era das sociedades pré-industriais, baseadas na produção e no trabalho material, ainda dependentes da natureza, foi substituída por uma sociedade de serviços, de produção imaterial, baseada na informação, na comunicação, na divisão social do trabalho. Mudanças tais, que nos permitem, visivelmente, constatar a diferença da realidade atual para a era da Revolução Industrial e das sociedades pré-industriais. (ROSSO, 2008, p. 30).

A revolução tecnológica propiciou a utilização da informática, da comuni-

19“Os trabalhadores devem desaprender a dedicação ao trabalho duramente adquirida e o apego emocional duramente conquistado ao local de trabalho, assim como o envolvimento pessoal no conforto desse ambiente." (BAUMAN, 1999, p. 120).

20“Os trabalhadores devem desaprender a dedicação ao trabalho duramente adquirida e o apego emocional duramente conquistado ao local de trabalho, assim como o envolvimento pessoal no conforto desse ambiente." (BAUMAN, 1999, p. 120). 
cação, o aumento da automação até mesmo em atividades primárias, atingindo diretamente os trabalhadores e dando ênfase ao trabalho imaterial ${ }^{21}$.

Mas, afinal, questiona-se como podemos caracterizar o trabalho imaterial e, a resposta está inserida em um contexto. As ditas "atividades de serviço" cresceram vertiginosamente como empregadores, serviços ligados à cultura, saúde, educação, serviços sociais, de comunicação, bancários, de telefonia, entre outros que surgiram com a revolução informática, ganharam monta e passaram a refletir uma nova realidade. (ROSSO, 2008, p. 33).

Contudo, não obstante ao ressaltado, mister se faz asseverar que, a partir do momento que há essa quebra de paradigmas da materialidade da indústria para a imaterialidade dos serviços, ganharam relevo práticas nefastas ao empregado, tais como a intensificação do trabalho por produção, imposição de metas abusivas e inalcançáveis, exigência de um grau de dedicação quase que exclusivo para com a empresa, sem ignorarmos, o aumento considerável de doenças decorrentes do trabalho, como síndromes do pânico, stress, entre tantas outras, que passaram a ser uma constante, demonstrando que, o que realmente importa na sociedade de consumo e em rede, são os resultados, em detrimento da própria saúde, integridade e dignidade do trabalhador.

Ocorreu, assim, a transição das atividades industriais para as atividades de serviço e, como consequência, todo esse desgaste físico, intelectual e emocional dos trabalhadores diretamente envolvidos. $\mathrm{E}$, sem querer ser pessimista, essa realidade atual nos permite ousar a prever que o capitalismo globalizado fará com que, em um futuro não muito distante, o setor industrial esteja tão reduzido em sua capacidade de empregar mão de obra, quanto hoje o setor primário (ROSSO, p. 33 e 37 ).

E, justamente, neste cenário, foi que Sadi Del Rosso, operou com a noção de mais-valia (ROSSO, p. 33), emprestada de Karl Marx, visando esclarecer esse momento transicional do trabalho material para o imaterial (MARX, 1988, p. 33). E defendeu que o conceito de mais-valia relativa se encaixa melhor à idéia de imaterialidade do trabalho.

$E$, assim, um grande desafio que se passa a enfrentar a partir desta nova e incontestável realidade está na valoração deste trabalho imaterial. A noção de

\footnotetext{
${ }^{21}$ Assim como a Revolução Industrial repercutiu sobre a classe trabalhadora dando origem à classe operária industrial, a Revolução Informacional gera a classe dos trabalhadores imateriais intensificados (ROSSO, 2008, p. 31).
} 
tempo trabalhado desenvolvida por Marx ${ }^{22}$ não responde mais ao modelo de trabalho imaterial.

Nas sábias palavras de Sadi Del Rosso, "um pesquisador faz uma descoberta e o valor dessa descoberta pode ser infinito ou nenhum" ${ }^{23}$, variando conforme seu potencial de mercantilização.

$\mathrm{E}$, deste modo, passa-se, a analisar a questão da propriedade dos inventos produzidos pelos empregados nas relações de trabalho subordinadas.

\section{A questão da propriedade dos inventos criados pelo empregado}

A fim de que o tema possa ser tratado com a profundidade e a importância peculiares, necessário se faz, antes de adentrar na questão dos inventos e da propriedade propriamente ditos, deixar claro que o Direito não é preciso quanto a essa questão.

De fato, há regramentos no tocante ao Direito Autoral - Lei $9610 / 98$ e a Propriedade Industrial - Lei 9279/76, contudo, não respondem a todas as demandas que surgem na sociedade de consumo e da informação, levando-se ainda em conta que, a dinâmica das relações sociais, por outro lado, em aspectos já abordados pela legislação, em muitos momentos, requer uma nova interpretação e aplicação, a fim de ganhar efetividade.

Nesta linha de raciocínio, o pensamento de Supiot demonstra que, a fim de alcançar o tão almejado equilíbrio e efetividade, temos que ter a sábia compreensão que "o Direito e a técnica participam de uma mesma cultura e avançam num mesmo ritmo”. Aduz que, “(...) não há dúvida de que o Direito pertence ao universo das técnicas. O Direito é mesmo uma das primeiras técnicas imateriais (...)." (SUPIOT, 2007, p. 141). A evolução do Direito do Trabalho, desde as Revoluções Francesa e Industrial, do capitalismo marxista, até o surgimento do Direito do Trabalho como ciência a partir de 1919, responsável pela imposição de limites

\footnotetext{
${ }^{22} \mathrm{~A}$ produção de valores-de-uso muda sua natureza geral por ser levada a cabo em benefício do capitalista ou estar sob o controle, Por isso, temos inicialmente de considerar o processo de trabalho à parte de qualquer estrutura social determinada. (MARX, 1988, p.1).

${ }^{23}$ Infinito se a descoberta pode ser comodificada, mercantilizada, transformada em mercadoria. 0 trabalho do pesquisador não é representado pelo tempo médio socialmente necessário. A faísca cerebral e a fogueira mental que conduziram à descoberta são de natureza distinta do tempo médio e isto the confere um potencial infinito de valor. Nenhum, caso se trate de pesquisa básica ou de pesquisa cujos resultados práticos não podem ser imediatamente transformados em mercadoria. (MARX, 1988, p. 34).
} 
a este atuar capitalista, reflete nitidamente essa estreita e visceral ligação do Direito com a técnica ao longo dos séculos. (SUPIOT, 2007, p. 142).

A grande sacada, o mote do raciocínio, essencial para compreensão do contexto e da conclusão, consiste em constatar que essa "função antropológica do Direito não desaparece de um tipo de técnica para outro" ${ }^{24}$, na verdade, ela se transmuda, e aqui reside a importância e a beleza da técnica do direito: dinâmica e efetiva.

O notório desafio dos tempos modernos reside em encontrar caminhos para que o Direito consiga acompanhar a velocidade e a complexidade das relações decorrentes dessa sociedade em rede. $E$, podemos ousar a asseverar que, o Direito rígido, invariável, inflexível e imutável não tem mais vez ${ }^{25}$.

O grande protagonista desse enredo passa a ser o Poder Judiciário, qual seja, encenando o papel primordial de aproximar as técnicas às exigências das demandas sociais que, justamente, a legislação não prevê ou estão em descompasso com a realidade.

Assim, a questão dos inventos criados pelos empregados e sua respectiva propriedade. A supracitada Lei 9279/96 regula os direitos e obrigações relativos à propriedade industrial, não se aplicando mais o artigo 454 da Consolidação das Leis do Trabalho, revogado desde os anos 70, pela Lei 5772/71, que dispunha sobre o assunto nas relações de trabalho subordinadas.

De fato, o Capítulo XIV, do Título I, reserva disposições destinadas a regular as invenções e os modelos de utilidade ${ }^{26}$ realizados por empregados ou prestadores de serviço. Destaca-se, no referido capítulo, os artigos 88, 90 e 91 da Lei 9279/96, que assim dispõem expressamente:

Artigo 88: A invenção e o modelo de utilidade pertencem exclusivamente ao empregador quando decorrerem de contrato de trabalho

\footnotetext{
${ }^{24} \mathrm{O}$ exame desses problemas permite compreender as relações que as técnicas não cessaram de manter com o Direito. Essas relações não se deixaram resumir a mera adaptação de um Direito que estaria por definição atrasado relativamente ao progresso técnico, nem a uma submissão desse progresso a princípios jurídicos imutáveis. O Direito, enquanto técnica, participou desde a origem da emergência das tecnologias da informação e da comunicação, mas seu conteúdo hoje evolui diante de nossos olhos para submeter a utilização dessas tecnologias a valores propriamente humanos. 0 Direito do Trabalho permanece, assim, um observador privilegiado das relações entre o Direito e a técnica. (SUPIOT, 2007, p.144).

${ }^{25} \mathrm{O}$ ideal de uma sociedade capaz de regular a si mesma se expressa, enfim, no grau de desenvolvimento contemporâneo da negociação coletiva e, de modo mais geral na contratualização das relações sociais. (SUPIOT, 2007, p.159).

${ }^{26} \mathrm{Na}$ invenção há a criação de algo totalmente novo, gera criação, inovação e pode ser patenteada, salvo nas hipóteses expressamente previstas nos artigos 10 e 18, ambos da Lei $n^{\circ}$ 9279/96; não se confundindo com o modelo de utilidade, quando o produto já existe, mas lhe criou uma nova funcionalidade.
} 
cuja execução ocorra no Brasil e que tenha por objeto a pesquisa ou a atividade inventiva, ou resulte esta da natureza dos serviços para os quais o empregado foi contratado.

§1 ${ }^{\circ}$ : Salvo expressa disposição contratual em contrário, a retribuição pelo trabalho a que se refere este artigo limita-se ao salário ajustado.

§2: Salvo prova em contrário, consideram-se desenvolvidos na vigência do contrato a invenção ou modelo de utilidade , cuja patente seja requerida pelo empregado ate 1 (um) ano após a extinção do vínculo empregatício.

(...)

Artigo 90: Pertencerá exclusivamente ao empregado a invenção ou o modelo de utilidade por ele desenvolvido, desde que desvinculado do contrato de trabalho e não decorrente da utilização dos recursos, meios, dados, materiais, instalações ou equipamentos do empregador.

Artigo 91: A propriedade de invenção ou de modelo de utilidade será comum, em partes iguais, quando resultar da contribuição pessoal do empregado e de recursos, meios, dados, materiais, instalações ou equipamentos do empregador, ressalvada expressa disposição contratual em contrário.

§1 ${ }^{\circ}$ : Sendo mais de um empregado, a parte que lhes couber será dividida igualmente entre todos, salvo ajuste em contrário.

§2: É garantido ao empregador o direito exclusivo de licença de exploração e assegurada ao empregado o direito de justa remuneração.

§3: A exploração do objeto da patente, na falta de acordo, deverá ser iniciada pelo empregador dentro do prazo de 1 (um) ano, contado da data de sua concessão, sob pena de passar à exclusiva propriedade do empregado a titularidade da patente, ressalvadas as hipóteses de falta de exploração por razões legítimas.

$\S 4^{\circ}$ : No caso de cessão, qualquer dos cotitulares, em igualdade de condições, poderá exercer o direito de preferência.

Assim sendo, podemos constatar que, o Direito, alinhado à técnica, se pre- 
ocupou em impor limites de atuação a situações decorrentes e cada vez mais ligada ao trabalho imaterial e à sociedade da informação, da comunicação, ligada em rede.

Ora, sendo assim, em uma análise superficial, a proposta do presente estudo cairia por terra, ou seja, não haveria mais por que se preocupar, pois o Direito já traria todas as soluções. Ledo engano, exatamente neste momento, a análise crítico-construtiva mencionada na introdução da obra ganha relevo, pois, o fato de haver normatização legal sobre o tema não encerrou o debate e a insegurança, na medida em que o trabalho imaterial e a sociedade em rede fazem surgir novas demandas e questionamento não abrangidos pela lei. Simplesmente ignorar e apresentar repetidamente respostas prontas não resolverá a questão e, como tudo isso ocorre numa velocidade ímpar, o Judiciário entra em cena, para aparar as arestas e oxigenar o Direito. Trata-se do dinamismo e efetividade preconizados, em contraponto às ultrapassadas rigidez e inflexibilidade.

Destarte, a questão precisa de novos contornos, necessita de parâmetros mais precisos e delimitados, a fim de que, de fato, possamos identificar a questão da propriedade dos inventos.

$\mathrm{Na}$ sociedade informacional e em rede, faz-se necessário o aprofundamento do estudo da propriedade intelectual. A questão vem sendo analisada pelo Judiciário Trabalhista como algo "novo". Alguns autores, inclusive, têm criticado o posicionamento do Judiciário Trabalhista em relação a estas "novas" propriedades, em razão de não alcançarem acertadamente a grandeza de seu significado nos julgamentos proferidos. Tecnicistas e legalistas, não conseguem fazer a correta adequação do Direito à técnica, a qual não se refere ao que está positivado tão somente, mas, pelo contrário, em conseguir um caminhar conjunto e efetivo em prol das soluções das demandas que se instauram.

Tanto assim o é, que o Tribunal Superior do Trabalho reconheceu em alguns julgados recentes o direito de propriedade ao empregado, e não ao empregador, ainda que desenvolvido o invento na constância da relação subordinada, por não representar o objeto do contrato e não haver disposição contratual expressa delegando a propriedade ao empregador.

Pode-se citar um acórdão, proferido pela Terceira Turma do Colendo Tribunal Superior do Trabalho, em fevereiro de 2010, considerado revolucionário, singular, quebrando os paradigmas preestabelecidos e, segundo alguns, imutáveis, para condenar a União, na qualidade de sucessora da extinta Rede 


\section{NILTON CESAR FLORES E JULIANA MONTEIRO}

Ferroviária Federal, a indenizar um ex-empregado que desenvolveu um instrumento de trabalho (modelo de utilidade) que a empresa até a data de hoje utiliza em prol de sua produtividade, alcançando a elevada monta de 390 mil dólares ${ }^{27}$.

$\mathrm{E}$, a partir do momento que a lacuna jurídica foi criada, outras decisões neste sentido foram igualmente proferidas, como um acórdão da Sétima Turma do Tribunal Superior do Trabalho que assegurou a um escriturário da Caixa Econômica Federal o direito de receber por softwares desenvolvidos por ele e utilizados pela instituição, tendo em vista que não fora contratado para esse tipo de atividade. Sendo enquadrado no $\$ 2^{\circ}$ do artigo 90 , recebendo uma justa remuneração ${ }^{28}$.

Em recente julgado, de fevereiro de 2012, em acórdão da Quarta Turma do Tribunal Superior do Trabalho, o mesmo raciocínio fora utilizado pela mais alta Corte Trabalhista, condenando a empresa a pagar 15\% dos lucros sobre a comercialização de um protetor de cabine para caminhonetes, conhecido como "Santo Antônio", a ex-gerente de produção, tendo em vista que a atividade de criação não estava prevista na função desenvolvida pelo empregado na empresa ${ }^{29}$.

Diante de todo o exposto, pode-se assim afirmar que, não obstante haja previsão legal sobre o tema, a matéria não é pacífica e o Judiciário, utilizando-se do Direito como técnica, vem adequando a lei ao caso concreto e trazendo soluções às demandas que surgem, de modo a exercer seu papel judicante com efetividade.

\section{CONSIDERAÇÕES FINAIS}

O momento transicional que vivemos nos insere em plena era de um capitalismo desorganizado, de uma sociedade capitalista globalizada, ligada em rede, da informação, da comunicação e, que desta feita produz reflexos em

\footnotetext{
${ }^{27}$ Relatora Rosa Maria Weber, então ministra do Tribunal Superior do Trabalho, sob o argumento de que "não se pode permitir a alienação da força de trabalho, no caso concretizada na forma de uma criação intelectual, em favor do empregador, sem que o empregado seja por isso remunerado." - RR 644489-89.2000.5.03.5555.

${ }^{28} \mathrm{RR}$ 7200-68.2004.5.13.0022.

${ }^{29} \mathrm{RR}$ 161200-59.2005.6.04.0404.
} 
toda a sociedade, sobremaneira nas relações sociais, mormente nas relações trabalhistas subordinadas.

Novas formas de exploração do trabalho, novos paradigmas, um capitalismo reinventado e adotado em quase todo o mundo e, formado por sociedades e economias interligadas, que fizeram com que o Direito, como técnica, tivesse que se readaptar para corresponder à velocidade com que essas transformações acontecem.

De fato, essa realidade se torna notória quando, fruto de toda essa transição paradigmática, novas demandas passam a surgir e o Direito passa a ter que atendê-las sob pena de cair no descrédito e gerar as tão temidas insatisfação e insegurança social.

De modo algum se trata de tarefa fácil, pelo contrário, é árdua a busca de esforços conjuntos em relação à atuação legislativa e judicante, sobretudo judicante, para conseguir atingir com maior rapidez e eficiência os resultados e respostas quase imediatas que esta sociedade veloz e interligada exige.

Neste contexto, a abordagem desenvolvida na presente obra teve o cerne de conduzir a uma visão, sempre destacada, crítico-construtiva, que permita uma conscientização dos déficits e demandas existentes, a fim de buscar soluções.

A questão da propriedade dos inventos produzidos pelo empregado demonstrou nitidamente essa transição mencionada e a necessidade de julgamentos efetivos e eficazes pelo Judiciário, não se baseando apenas na lei, ou seja, não há mais espaços para juízes autômatos que simplesmente decoram e aplicam o que está positivado na lei.

A sociedade atual é tão dinâmica e veloz que as leis editadas, depois do longo processo legislativo ao qual se submetem, nascem sob o estigma de estarem desatualizadas, isto é, em descompasso com a realidade e, mais uma vez, destaca-se a atividade interpretativa dos operadores do direito para suprir as lacunas da lei e garantir a segurança e o equilíbrio das relações sociais.

Conceder a propriedade ao empregado, sim, desde não faça parte das suas funções e não haja previsão expressa em contrário no contrato entre as partes. Registre-se que não se trata de descumprir a lei, sobremaneira, a finalidade maior se revela na configuração do tão almejado equilíbrio. 
De igual sorte, não se trata de formular respostas prontas, mas sim, como sabiamente adverte Bauman, "urge questionarmos as premissas supostamente inquestionáveis do nosso modo de vida, em prol da humanidade e de nós mesmos." (BAUMAN, 1999, p 11).

Um comentário que não pode deixar de ser registrado, diante da sociedade em rede e interligada, é que, os meios propostos de solução surtem efeitos em momentos e em realidades diversas, e que o fato de dar certo em outros países, embora ligados por uma economia globalizada, não necessariamente, funcionará em nosso país e vice versa.

Concentração de capital, competitividade, concorrência, velocidade, tecnologia, informação, comunicação, eficiência, exigências da sociedade atual e reflexos de um capitalismo selvagem e desenfreado. A grande questão reside em delimitar aonde vamos chegar e o que podemos fazer.

A questão precisa de novos contornos, de parâmetros mais precisos e delimitados, a fim de que, de fato, possamos identificar a questão da propriedade dos inventos criados pelos empregados na constância de suas relações de emprego, bem como tantas outras que já existem e as que estão por surgir.

\section{REFERÊNCIAS BIBLIOGRÁFICAS}

BAUMAN, Zygmunt. Globalização: As consequências humanas. Tradução: Marcus Penchel. Rio de Janeiro: Zahar, 1999.

BITTAR, Eduardo Carlos Bianca. O Direito na Pós-modernidade. São Paulo: Forense Universitária, 2005.

BRASIL. Lei no 9279 de 14 de maio de 1996. Regula direitos e obrigações relativos à propriedade industrial. Disponível em: <http://www.planalto.gov. br/ccivil_03/leis/ 19279.htm>. Acesso em: 20 de ago. de 2013. 
CAPRA, Fritjof. As conexões ocultas: ciência para uma vida sustentável. Tradução Marcelo Brandão Cipolla. São Paulo: Cultrix, 2005.

DESTARTES, René. Discurso do Método. Tradução: Maria Ermantina Galvão. São Paulo: Martins Fontes, 2001.

FARIA, José Eduardo e Celso Fernandes. A Sociologia Jurídica no Brasil. Porto Alegre: Sergio Antônio Fabris, 1991.

GIDDENS, Anthony. As consequências da modernidade. Tradução Raul Fiker. São Paulo: UNESP, 1991.

MARX, Karl. O Capital. Volume I - Parte III - Capítulo VII - Processo de Trabatho e Processo de produção de Mais Valia. Coleção Os Economistas. São Paulo: Nova Cultural, 1988.

ROSSO, Sadi Dal. Mais trabalho: A intensificação do labor na sociedade contemporânea. São Paulo: Bomtempo, 2008.

SANTOS, Boaventura de Sousa. A Crítica da Razão Indolente. Contra o desperdício da experiência. Vol. 1 - Para um novo senso comum: a ciência. 0 direito e a política na transição paradigmática. São Paulo: Cortez, 2000.

SUPIOT, Alain. Homo Juridicius. Ensaio sobre a função antropológica do Direito. Tradução Maria Ermantina de Almeida Prado Galvão. São Paulo: Martins Fontes, 2007. 


\section{LISTA DE ACÓRDÃOS ANALISADOS:}

PODER JUDICIÁRIO. Tribunal Superior do Trabalho. RR 7200-68.2004.5.13.0022. Disponível em: <http://ext02.tst.jus.br/pls/ap01/ap_red100.resumo?num_ int=478911\&ano_int= 2008\&qtd_acesso=5939449>. Acesso em: 10 de ago. de 2013.

. Tribunal Superior do Trabalho. RR 161200-59.2005.6.04.0404. Disponível em: <http://ext02.tst.jus.br/pls/ap01/ap_red100.resumo?num_ int=478911\&ano_int=2008\&qtd_acesso=9874563 . Acesso em: 10 de ago. de 2013.

- Tribunal Superior do Trabalho. RR 644489-89.2000.5.03.5555. Disponível em: < http://ext02.tst.jus.br/pls/ap01/ap_red100.resumo?num_ int=478911\&ano_int=2008\&qtd_acesso=39335739 >. Acesso em: 10 de ago. de 2013.

Artigo recebido em: 13.08.2013

Revisado em: 11.09.2013

Aprovado em: 07.10.2013 